\title{
Dual Band Defected Ground Microstrip Patch Antenna for WLAN/WiMax and Satellite Application
}

\author{
Neha Ahuja \\ Student
}

Rajesh Khanna
Professor

\author{
Jaswinder Kaur \\ Lecturer
}

\author{
Department of Electronics \& Communication Engineering \\ Thapar University, Patiala, Punjab
}

\begin{abstract}
A microstrip patch antenna for Wi-Max and GSM application is proposed. The antenna has a frequency bandwidth of $1.24 \mathrm{GHz}(4.6053 \mathrm{GHz}-5.8481 \mathrm{GHz})$ for WLAN and Wi-Max and $1.04 \mathrm{GHz}(6.124 \mathrm{GHz}-7.16$ $\mathrm{GHz}$ ) for Satellite application. The microstrip antenna has a planar geometry and consists of a defected ground, a substrate, a patch, a feed, one slot in patch and a defected ground which consists of a pie (П) slot and reduced area from all three sides except the feed side. The basic theory and design are analyzed, and simulation using CST Microwave Studio commercial software is employed to optimize the antenna's properties. Results show that the proposed antenna has promising characteristics for WiMax, WLAN and Satellite application at $5.5 \mathrm{GHz}$ frequency for WiMax, $5.2 \mathrm{GHz}$ and $5.8 \mathrm{GHz}$ for WLAN and $6-7 \mathrm{GHz}$ for satellite application respectively. The microstrip patch antenna has been analysed for various dimensions of ground and slots respectively.
\end{abstract}

\section{General Terms}

Microstrip line feed, pie shape and Microstrip Antenna.

\section{Keywords}

Defected Ground Structure, Wi-Max Communication Standard, WLAN Communication Standard and CST Microwave Studio.

\section{INTRODUCTION}

The microstrip patch antennas have many advantages such as small size, low-cost fabrication, low profile, light weight, conformability, ease of installation and integration with feed networks but it has one serious limitations i.e. these antennas have very narrow bandwidth characteristics as it limits the frequency ranges over which the antenna can perform satisfactorily [4]

These features of patch antennas are major designing considerations of practical patch antenna. In wireless communication systems, the IEEE 802.11 standard was proposed in 1997 for WLANs application. The bands for WLAN application are $2.4 \mathrm{GHz}(2.400 \mathrm{GHz}$ to 2.484 $\mathrm{GHz}), 5.2 \mathrm{GHz}(5.150 \mathrm{GHz}$ to $5.350 \mathrm{GHz})$ and $5.8 \mathrm{GHz}$ $(5.725 \mathrm{GHz}$ to $5.825 \mathrm{GHz})$. The name WiMAX was created by the WiMAX forum which was formed in June 2001 to promote conformity and interoperability of the standard. The WiMAX Forum has published three licensed spectrum profiles: $2.5 \mathrm{GHz}$ (2.5-2.69 GHZ), $3.5 \mathrm{GHz}$ (3.4-3.69 GHZ) and $5.5 \mathrm{GHz}$ (5.25-5.85 GHZ). Worldwide Interoperability for Microwave Access (Wi-MAX) technology [5] is the most rapidly growing area in the modern wireless communication [1].
This gives users the mobility to move around within a broad coverage area and still be connected to the network. This provides greatly increased freedom and flexibility. For the home user, wireless has become popular due to ease of installation, and location freedom. Naturally, these applications require antennas. This being the case, portable antenna technology has grown along with mobile and cellular technologies. It is important to have the proper antenna for a device. The proper miniaturized antenna will improve transmission and reception, reduce power consumption, last longer and improve marketability of the communication device.

The narrow bandwidth is the major drawback of microstrip patch antenna. Many approaches can be implemented to enhance bandwidth of microstrip patch antenna. But the most unique technique to reduce patch size is to defect the ground. While comparing the antenna with the defected ground structure and the antenna without defect, the antenna implementing defected ground structure reduces the size [9]. The percentage of reduction depends upon the defected ground area.

Defected Ground Structure constructed disturbs the shielded current distribution depending on the defect's shape and dimension. The input impedance and current flow of antenna is then influenced by the disturbance at the shielded current distribution due to DGS structure. The DGS structure can also control the excitation and electromagnetic waves propagating through the substrate layer [8].

In this paper, microstrip patch antenna for WiMax and WLAN application. $5.5 \mathrm{GHz}(5.250 \mathrm{GHz}$ to $5.850 \mathrm{GHz})$ for WiMax band, $5.2 \mathrm{GHz}(5.150 \mathrm{GHz}$ to $5.350 \mathrm{GHz})$ and 5.8 $\mathrm{GHz}(5.72 \mathrm{GHz}$ to $5.82 \mathrm{GHz})$ for WLAN band and $6 \mathrm{GHz}$ $(6 \mathrm{GHz}$ to $7 \mathrm{GHz})$ for Satellite application is designed and simulated using CST Microwave Studio [4]. The proposed patch antenna resonates at $5.47 \mathrm{GHz}$ and $6.4 \mathrm{GHz}$ respectively covering WLAN $5.2 \mathrm{GHz}$, WLAN $5.8 \mathrm{GHz}$, WiMax $5.5 \mathrm{GHz}$ and Satellite $6 \mathrm{GHz}$.

The designed antenna has been studied for different slot dimensions of the patch, pie slot dimensions and the rest of dimensions of the ground.

\section{GEOMETRY OF MICROSTRIP PATCH ANTENNA}

In this antenna, the substrate has a thickness $\mathrm{h}=1.6 \mathrm{~mm}$ and a relative permittivity $\varepsilon_{\mathrm{r}}=4.4$. The length and width of patch are $\mathrm{L}=18.84 \mathrm{~mm}$ and $\mathrm{W}=38 \mathrm{~mm}$ respectively. The length and width of substrate are $\mathrm{L}=22.83 \mathrm{~mm}$ and $\mathrm{W}=45.154 \mathrm{~mm}$ respectively. The structure for ground used 
is defected ground structure. The ground has been reduced from all the sides with a pie $(\Pi)$ at the centre of the ground. Edges along the width are called radiating edges and that along the length are called non radiating edges [2]. The main concept behind the designed structure is to implement DGS structure to reduce the antenna size [10] and to enhance the bandwidth of the antenna. Microstrip patch antenna can be fed by different methods like microstrip line feed, coaxial probe feed, aperture coupling, electromagnetic coupling and coplanar waveguide (CPW). In this work, microstrip line $(50 \mathrm{ohm})$ feed has been used. In this design we have used a defected ground structure which gives the good resonance. Antenna is designed for a resonating frequency of $5.5 \mathrm{GHz}$ and $6.4 \mathrm{GHz}$ and is analyzed using CST Microwave Studio software. For the designing of rectangular microstrip antenna, the following relationships are used to calculate the dimensions of rectangular microstrip patch antenna. The papers have been studied for designing a dual band antenna to obtain good results [6] [7].

$$
\begin{aligned}
& \varepsilon_{\text {reff }}=\frac{\varepsilon_{r}+1}{2}+\frac{\varepsilon_{r}-1}{2}\left[1+12 \frac{h}{W}\right]^{-\frac{1}{2}} \\
& L_{e f f}=\frac{c}{2 f_{0} \sqrt{\varepsilon_{\text {reff }}}} \\
& \frac{\Delta L}{h}=0.412 \frac{\left(\varepsilon_{\text {reff }}+0.3\right)\left(\frac{W}{h}+0.264\right)}{\left(\varepsilon_{\text {reff }}-0.258\right)\left(\frac{W}{h}+0.8\right)} \\
& L=L_{\text {eff }}-2 \Delta L \\
& f_{r}=\frac{1}{2 L \sqrt{\varepsilon_{r} \varepsilon_{0} \mu_{0}}}=\frac{v_{0}}{2 L \sqrt{\varepsilon_{r}}} \\
& W=\frac{1}{2 f_{r} \sqrt{\mu_{0} \varepsilon_{0}}} \sqrt{\frac{2}{\varepsilon_{r}+1}} \\
& L_{g}=6 h+L \\
& \begin{array}{l}
W \\
W_{g}
\end{array}=6 h+W \\
& \text { where, }
\end{aligned}
$$

$\mathrm{h}=$ substrate thickness

$\mathrm{L}=$ length of patch

$L_{\text {eff }}=$ effective length

$\mathrm{W}=$ width of patch

$\mathrm{c}=$ speed of light

$f_{0}=$ resonant frequency

$\varepsilon_{r}=$ relative permittivity

$\varepsilon_{\text {reff }}=$ effective permittivity

$L_{g}=$ Length of ground plane

$W_{g}=$ Width of ground plane

\section{DESIGN PARAMETERS}

Figure 1(a) and 1(b) show the front view geometry and the structure designed on CST Microwave Studio software of proposed microstrip line fed patch antenna with dual band operation for WLAN/WiMax and Satellite application.

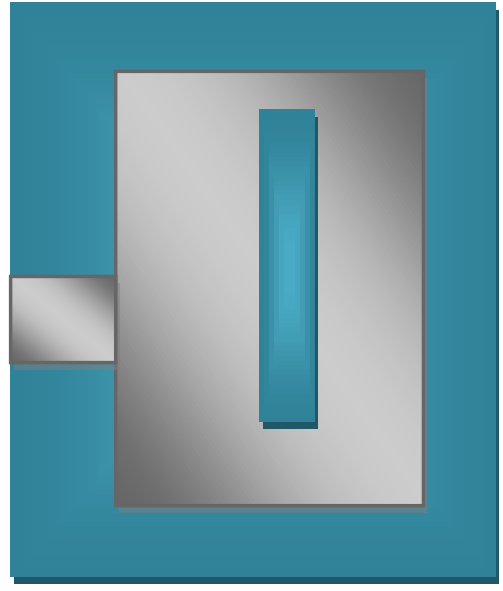

Figure 1 (a): Front view geometry of proposed antenna

The dimensions and feed point location for proposed antenna have been optimized so as to get the best possible impedance match to the antenna.

The following parameters are used for design of proposed antenna.

Substrate permittivity $=4.4$

Thickness of substrate $=1.6 \mathrm{~mm}$

Length of patch $(\mathrm{L})=18.84 \mathrm{~mm}$

Width of patch $(\mathrm{W})=38 \mathrm{~mm}$

Length of Substrate $(\mathrm{Ls})=22.83 \mathrm{~mm}$

Width of Substrate $(\mathrm{Ws})=45.154 \mathrm{~mm}$

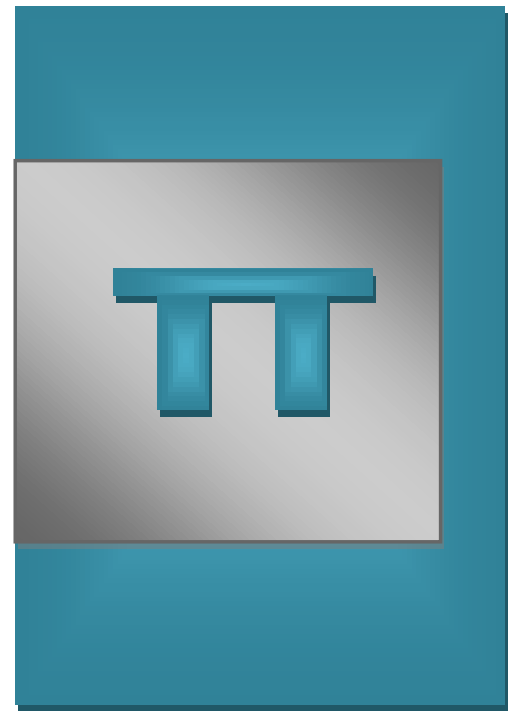

Figure 1 (b): Back view geometry of proposed antenna 4. SIMULATED RESULTS

The $S_{11}$ parameters for the designed antenna were calculated and the simulated return loss results are shown in Figure 2. The bandwidth of $1.24 \mathrm{GHz}(4.6053 \mathrm{GHz}-$ $5.8481 \mathrm{GHz}$ ) for WLAN / WiMax has been achieved as shown in Figure 3(a) resonating at $5.5 \mathrm{GHz}$ with the corresponding value of return loss as $-27.26 \mathrm{~dB}$. The bandwidth of $1.04 \mathrm{GHz}(6.124 \mathrm{GHz}-7.16 \mathrm{GHz})$ for Satellite application has been achieved as shown in figure 3(b) resonating at $6.4 \mathrm{GHz}$ with the corresponding value of return loss as $-20.77 \mathrm{~dB}$. The antenna covers the WLAN standard (5.2 GHz and 5.8 GHz band) / WiMax standard 
5.5 GHz band and Satellite band $6.4 \mathrm{GHz}(6 \mathrm{GHz}-7$ $\mathrm{GHz})$.

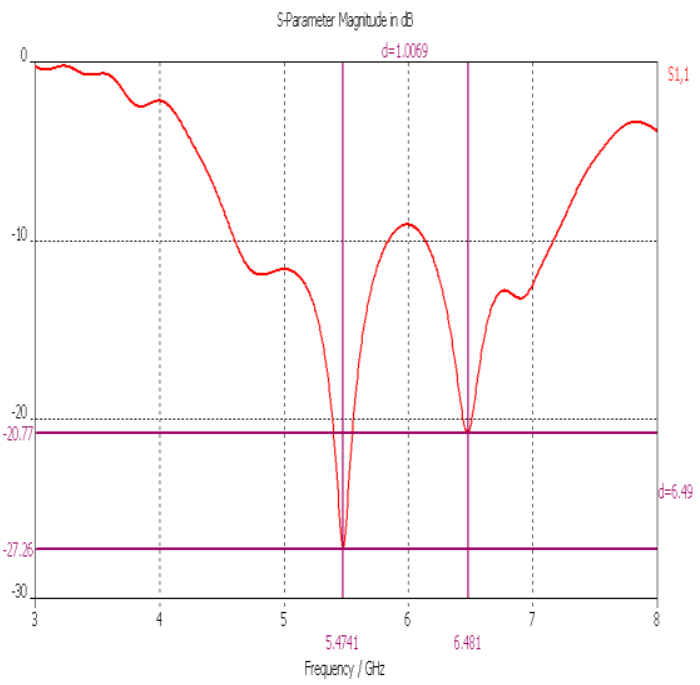

Figure 2: Simulated Return Loss Curve

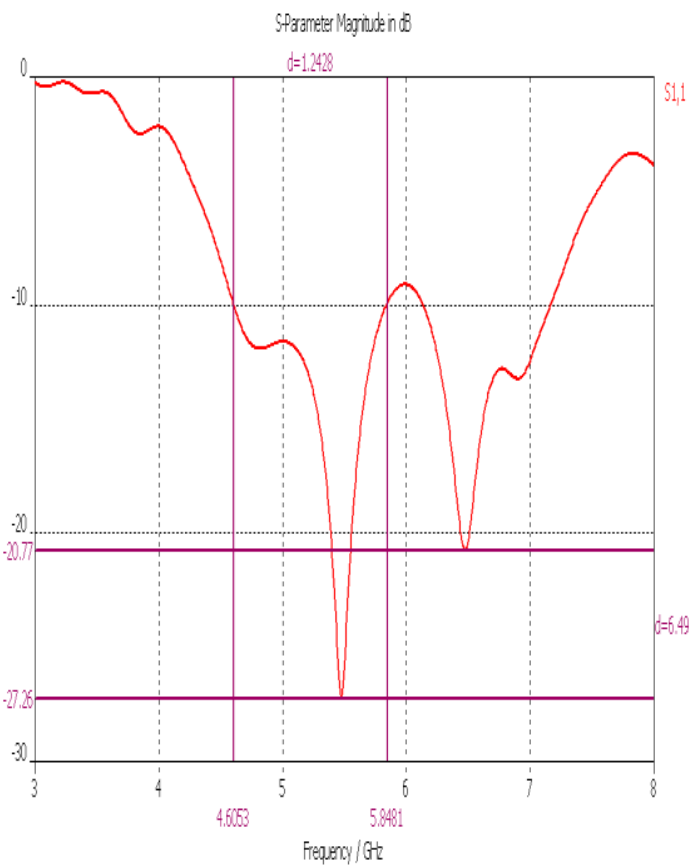

Figure 3(a): Bandwidth plot for WLAN / WiMax band

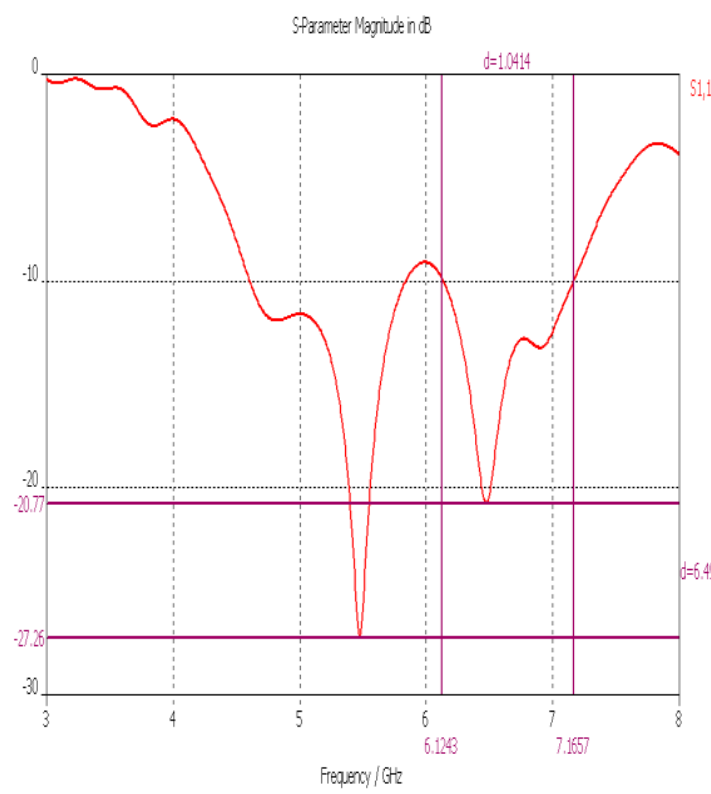

Figure 3(b): Bandwidth plot for Satellite band

The achieved value of return loss is good enough and frequency is closed enough to the specified frequency band $5.5 \mathrm{GHz}$ for WiMax application / 5.2 GHz and 5.8 GHz for WLAN application and $6 \mathrm{GHz}$ for Satellite application. The return loss value for $5.5 \mathrm{GHz}$ is $-27.26 \mathrm{~dB}$, and for $6.4 \mathrm{GHz}$ is $20.77 \mathrm{~dB}$ suggests that there is good matching at the frequency points below the $-10 \mathrm{~dB}$ region.

The antenna consists of a slot in patch and the defected ground structure. The defected ground structure consists of reduced ground structure from three sides and a pie shape slot at centre of the ground. The antenna was varied for different values of slot of patch and pie slot of ground. The defected ground structure

The maximum achievable gain over the entire frequency band of $5.5 \mathrm{GHz}$ is $4.262 \mathrm{~dB}$ and $6.4 \mathrm{GHz}$ is $4.668 \mathrm{~dB}$.

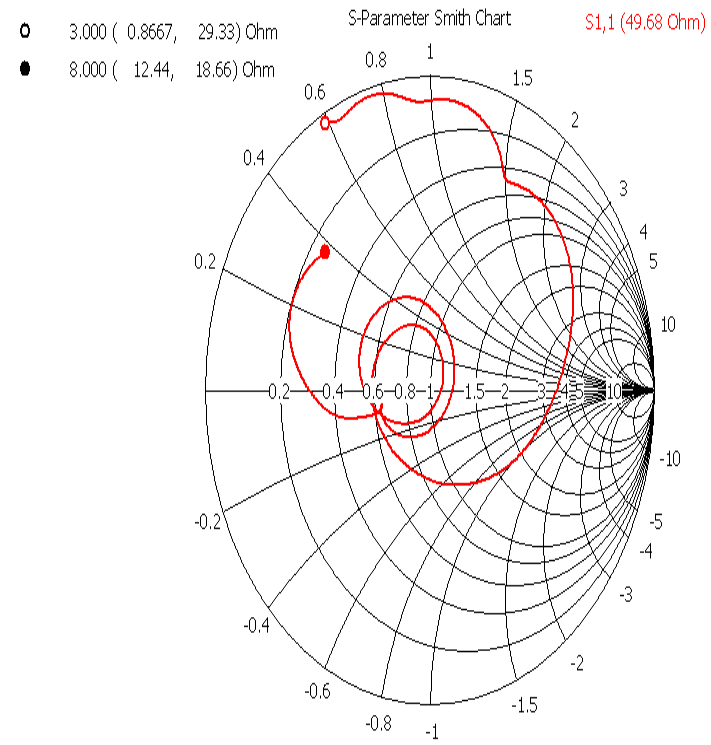

Figure 4: Curve showing antenna characteristic impedance 


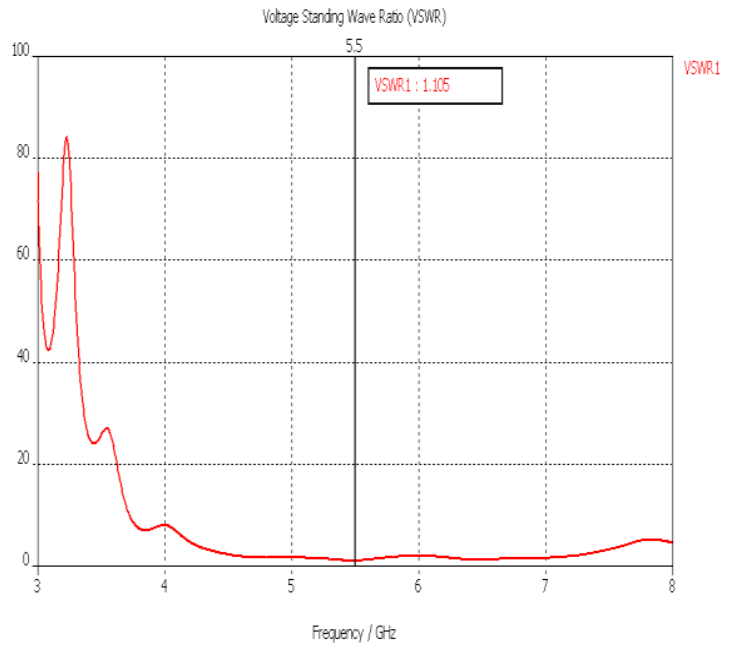

Figure 5: VSWR curve at $5.5 \mathrm{GHz}$ frequency

The achieved antenna impedance is $49.68 \mathrm{ohm}$ as shown in Figure 4 , which is very close to the required impedance of $50 \mathrm{ohm}$. The VSWR ratio at $5.5 \mathrm{GHz}$ frequency is $1: 1.105$ is shown in Figure 5(a), the VSWR ratio at $5.8 \mathrm{GHz}$ frequency is $1: 1.203$ is shown in Figure 5(b), it should lie in between 1 and 2 .

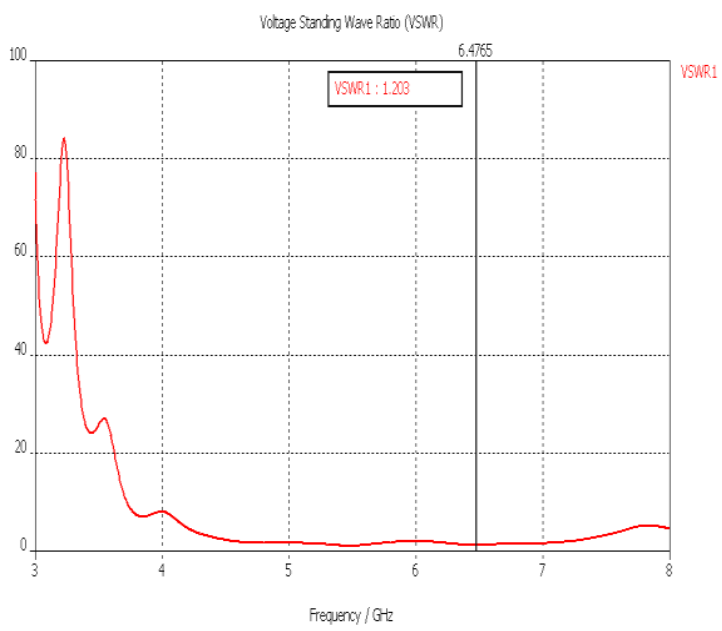

Figure 5: VSWR curve at $6.4 \mathrm{GHz}$ frequency

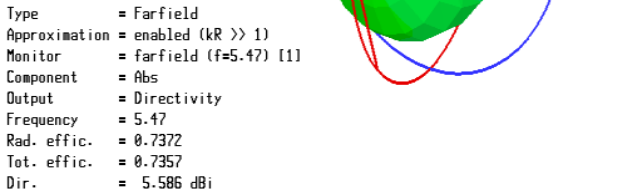

Figure 6(a): 3-D Radiation Pattern of Patch antenna showing directivity at $5.5 \mathrm{GHz}$
Figure 6(a) shows the simulated 3-D radiation pattern showing directivity at $5.5 \mathrm{GHz}$. Figure 6(b) shows the simulated 3-D radiation pattern showing directivity at 6.4 GHz. Figure 7(a) shows the simulated 3-D radiation pattern showing gain at $5.5 \mathrm{GHz}$. Figure 7(b) shows the simulated 3 -D radiation pattern showing gain at $6.4 \mathrm{GHz}$. It shows that proposed antenna radiates in omni-directional nature. It also shows that the directivity of proposed antenna is $\mathbf{5 . 5 8 6}$ $\mathrm{dBi}$ at resonating frequency of $5.5 \mathrm{GHz}$. It also shows that the directivity of proposed antenna is $5.903 \mathrm{dBi}$ at resonating frequency of $6.4 \mathrm{GHz}$.

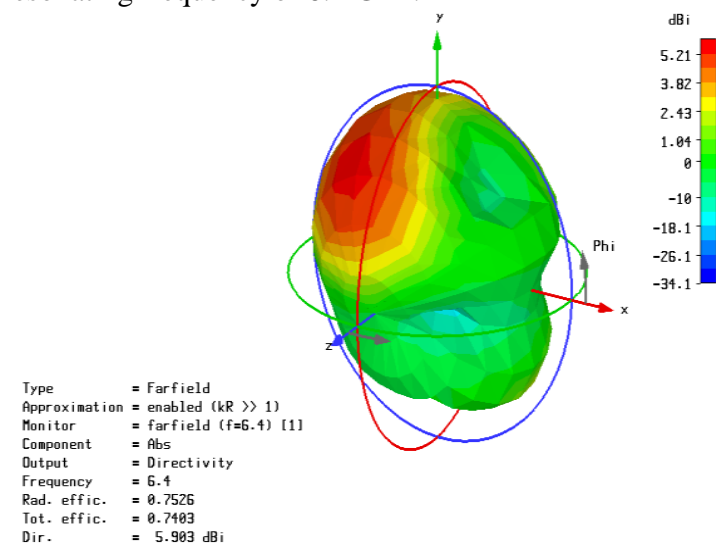

Figure 6(b): 3-D Radiation Pattern of Patch antenna showing directivity at $6.4 \mathrm{GHz}$

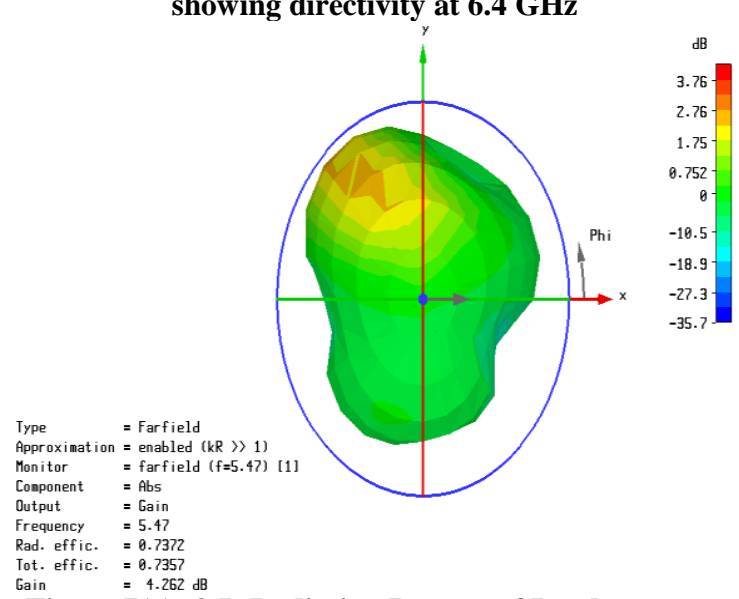

Figure 7(a): 3-D Radiation Pattern of Patch antenna showing Gain at $5.5 \mathrm{GHz}$

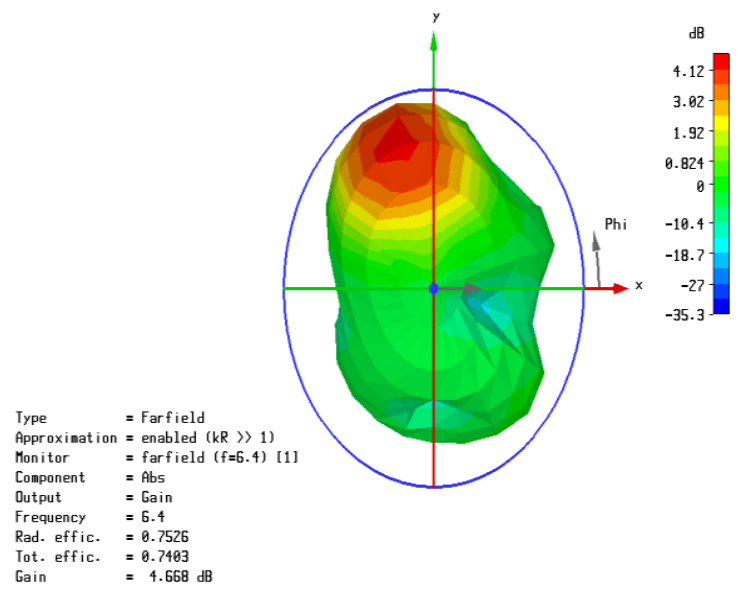

Figure 7(b): 3-D Radiation Pattern of Patch antenna showing Gain at $6.4 \mathrm{GHz}$ 


\section{CONCLUSION}

A microstrip line fed dual frequency microstrip patch antenna has been designed and simulated using CST Microwave Studio software. This antenna resonate for WLAN/WiMax band, the frequency band of $5.15 \mathrm{GHz}-$ $5.82 \mathrm{GHz}$ covering $5.2 \mathrm{GHz}$ and $5.8 \mathrm{GHz}$ WLAN communication standard and $5.5 \mathrm{GHz}$ WiMax standard and the frequency band $6 \mathrm{GHz}$ to $7 \mathrm{GHz}$ covering satellite standard. The simulated impedance bandwidth at the $5.5 \mathrm{GHz}$ band is $1.24 \mathrm{GHz}$ with the corresponding value of return loss as $-27.26 \mathrm{~dB}$ which is enough for matching and frequency is closed enough to the specified frequency band feasible for WiMax/WLAN application. The simulated impedance bandwidth at the $6.4 \mathrm{GHz}$ band is $1.04 \mathrm{GHz}$ with the corresponding value of return loss as $-20.77 \mathrm{~dB}$ which is enough for matching and frequency is closed enough to the specified frequency band feasible for Satellite application. This return loss value i.e. $-27.26 \mathrm{~dB}$ and $-20.77 \mathrm{~dB}$ suggests that there is good impedance matching at the frequency point below the $-10 \mathrm{~dB}$ region.

An omni-directional radiation pattern result has been obtained which seems to be adequate for the envisaged applications. This antenna has directivity of $5.586 \mathrm{dBi}$ at $5.5 \mathrm{GHz}$ and $5.983 \mathrm{dBi}$ at $6.4 \mathrm{GHz}$ of the wireless communication (WiMax/WLAN and Satellite respectively). But this antenna has a low gain of $4.262 \mathrm{~dB}$ at $5.5 \mathrm{GHz}$ frequency band and $4.668 \mathrm{~dB}$ at $6.4 \mathrm{GHz}$ of the wireless communication (WiMax/WLAN and Satellite respectively) with a good impedance matching of 49.68 ohm.

However, the size of the microstrip antenna, reported here, is not very small. The gain of this antenna is small but it can be increased using gain enhancement techniques. The microstrip patch antenna using DGS structure reduces the gain and directivity if that particular antenna in which it has been implemented. The final technique left to enhance the gain and directivity of the microstrip patch antenna using DGS structure is the use of Meta Materials. Work is going on to achieve even better results with good axial ratio over a wide bandwidth.

\section{ACKNOWLEDGEMENTS}

The authors are grateful to referees for their valuable comments.

\section{REFRENCES}

[1]. P. Pigin, "Emerging mobile WiMax antenna technologies", IET Communication Engineer, October/ November 2006.

[2]. R.Garg, P.Bhartia, I.Bahl, A.Itipiboon, "Microstrip antenna design handbook", Artech House, Boston London, 2000.

[3]. James,J.R., and P.S.Hall, "Handbook of Microstrip Antennas", Vol.1, London: Peter Peregrinus Ltd., 1989.

[4]. C.A. Balanis, "Antenna Theory Analysis and Design", third edition, Wiley, New Jersey, 2005.

[5]. http:en.wiki .edia.org/wiki/WiMAX/Wlan.

[6]. Islam, F. ; Ali, M. ; Majlis, B.Y. ; Misran, N. "Design, simulation and fabrication of a microstrip patch antenna for dual band application", International Conference on Electrical and Computer Engineering, Dec. 2008, pp 799 - 802.

[7]. Palit, S.K. Hamadi, A, "Design and development of wideband and dual-band microstrip antennas", Microwaves, Antennas and Propagation, IEE Proceedings, vol. 146, no. 1, Feb 1999, pp 35 - 39.

[8]. Rajeshwar Lal Dua, Himanshu Singh, Neha Gambhir, "2.45 GHz Microstrip Patch Antenna with Defected Ground Structure for Bluetooth", International Journal of Soft Computing and Engineering (IJSCE) ISSN: 2231-2307, Volume-1, Issue-6, January 2012.

[9]. L. H. Weng, Y. C. Guo, X. W. Shi, and X. Q. Chen "An Overview On Defected Ground Structure" Progress In Electromagnetics Research B, Vol. 7, 173-189, 2008.

[10]. Jose Alfredo Tirado-Mendez ${ }^{1}$, Hildeberto JardonAguilar ${ }^{1}$, Flavio Iturbide-Sanchez ${ }^{2}$, Israel GarciaRuiz $^{3}$, Victoria Molina-Lopez ${ }^{1}$, and Rene AcevoHerrera ", "A Proposed Defected Microstrip Structure (Dms) Behavior For Reducing Rectangular Patch Antenna Size" Microwave And Optical Technology Letters / Vol. 43, No. 6, December 202004. 